\title{
MINERAÇÃO DE PROCESSOS EM UM ÓRGÃO PÚBLICO: ESTUDO DA DIRETORIA DE LOTEAMENTOS DA PREFEITURA MUNICIPAL DE LONDRINA (PR)
}

\author{
PROCESS MINING IN A PUBLIC AGENCY: STUDY OF LONDRINA \\ MUNICIPALITY DIVISION OF ALLOTMENTS (PR)
}

\author{
Rodrigo Libanez Melan \\ Hewerton Fernandes da Silva ${ }^{2}$ \\ Saulo Fabiano Amâncio-Vieira ${ }^{3}$ \\ Evandro Baccarin ${ }^{4}$
}

\begin{abstract}
Resumo: A mineração de processos é uma técnica que vem contribuir com a análise de elevada quantidade de dados e oferece potencias de ganho analítico, o que a tornou aderente aos trabalhos aqui descritos e desenvolvidos na Diretoria de Loteamentos da Prefeitura Municipal de Londrina (PR). Dificuldades no atendimento às demandas, expressas, por exemplo, em elevados prazos em seus processos, motivaram a aplicação da técnica. Esta objetivou caracterizá-los e identificar possibilidades de ganhos de eficiência e eficácia. A mineração de processos não foi a forma exclusiva de estudo, pois utilizaram-se indicadores censitários e método qualitativo para tanto, com avaliação caso a caso e elaboração de fluxograma embasadas em diretrizes legais. $\mathrm{O}$ trabalho caracterizou-se, pois, como um estudo de caso misto, descritivo e exploratório, com recorte longitudinal, baseado em dados primários e secundários e prescritivo. Observou-se que os processos se fizeram altamente complexos, morosos e pouco padronizados, motivando a sugestão de melhorias quanto ao seu tempo de execução e de espera, as quais impactam o custo, qualidade e flexibilidade por eles abarcados. Além dessas contribuições práticas, o estudo sugeriu ganhos potenciais da mineração de processos mesmo em cenários com dados insatisfatórios à metodologia.
\end{abstract}

Palavras-chave: Mineração de processos. Paraná. Londrina. Gestão pública. Loteamentos.

Abstract: Process mining is a technique that contributes to evaluation of a large amount of data and offers potential analytical gains, which made it adhere to work described and developed in Division of Allotments of the Municipality of Londrina (PR). Difficulties in handle demands, expressed, for example, in long periods in their processes, motivated the application of technique. This aimed to characterize them and identify possibilities of gains in efficiency and effectiveness. Process mining was not exclusive form of study, as census indicators and a qualitative method were used for this, with case-by-case assessment and development of a flowchart based on legal guidelines. The work was characterized, therefore, as mixed, descriptive and exploratory case study, with a longitudinal cut, based on primary and secondary data and prescriptive. It was observed that processes became highly complex, time consuming and not very standardized, motivating suggestion of improvements regarding their execution and waiting time, which may impact cost, quality and flexibility they cover. In addition to these practical contributions, the study suggested potential gains from process mining even in scenarios with unsatisfactory data on the methodology.

Keywords: Process mining. Paraná. Londrina. Public management. Allotments.

\footnotetext{
(ㄱ)1 Mestre, Universidade Estadual de Londrina - UEL. Londrina, Paraná - Brasil. rodrigo.libanezm@gmail.com

(1) 2 Mestre, Pontifícia Universidade Católica do Paraná - PUCPR. Londrina, Paraná - Brasil. hewertonsilva @ yahoo.com.br

(1) 3 Doutor, Universidade Estadual de Londrina - UEL. Londrina, Paraná - Brasil. saulo@ uel.br

(C) ${ }^{4}$ Doutor, Universidade Estadual de Londrina - UEL. Londrina, Paraná - Brasil. bacarin@uel.br
}

\section{Cite como}

American Psychological Association (APA)

Melan, R. L., Silva, H. F., Amâncio-Vieira, S. F., \& Baccarin, E. (2020, jul./dez.). Mineração de processos em um órgão público: estudo da diretoria de loteamentos da Prefeitura Municipal de Londrina (PR). Revista Inovação, Projetos e Tecnologias, São Paulo, 8(2), 221-234. https://doi.org/10.5585/iptec.v8i2.17620. 


\section{Introdução}

O Estado brasileiro tem encontrado dificuldades para gestão dos recursos necessários ao aumento do bem-estar social, notadamente pelas maiores diferenças entre suas receitas e despesas, o que se materializa nos níveis elevados de compromissos assumidos pelos orçamentos que controla (Ferrer, 2018). De outra forma, os esforços envidados na consecução de seu papel em elevar o bem-estar se mostraram vítimas de elementos históricos do país, como o personalismo político, o autoritarismo, o clientelismo, os mecanismos de reprodução da desigualdade e o corporativismo, imbuindo os esforços com sucesso parcial (Cantarino \& Müller, 2020). Tais argumentos são relevantes na medida em que permitem reiterar a importância das ações que serão aqui descritas, corroborando a centralidade da instituição que as empreendeu e dos resultados obtidos. Assim, com gênese motivada no apoio às organizações públicas e na busca de maior qualidade nos serviços e produtos disponibilizados por estas, o Núcleo Interdisciplinar de Gestão Pública (NIGEP) nasceu do empenho de docentes da Universidade Estadual de Londrina (localizada no estado do Paraná) em transferir à sociedade conhecimentos gerados nessa instituição de ensino, o que é vislumbrado em seus objetivos, quais sejam, entre outros, "produzir novas metodologias de trabalho que permitam maior eficiência, eficácia e efetividade em gestão pública na esfera regional" (Universidade Estadual de Londrina [UEL], 2020).

O projeto que se descreverá neste trabalho refere-se à parceria firmada entre a Prefeitura do Município de Londrina (PML) e o NIGEP, com intuito de elevar a qualidade de serviços prestados por diversas secretarias contidas naquele órgão. No primeiro semestre de 2019, formalizou-se a parceria, dando início aos trabalhos na PML, os quais desdobraram-se em nove subprojetos. Especificamente, será abordado o trabalho realizado na Secretaria Municipal de Obras e Pavimentação (SMOP), em sua Diretoria de Loteamentos. Antes, contudo, elencam-se alguns dados da cidade de Londrina, visando à contextualização do projeto ao leitor.

Londrina está na região norte do Paraná e possui a segunda maior população do estado, estimada em mais de 569 mil habitantes em 2019, sendo predominantemente urbana $(97,4 \%)$. Apresenta produto interno bruto (PIB) composto majoritariamente por atividades de comércio e serviço, seguidas pela indústria (nesta ordem, cerca de $80 \%$ e $17 \%$ em 2017) (Prefeitura de Londrina, 2020). O PIB da cidade em 2017 foi de mais de R 19 bilhões, sendo o terceiro maior do estado e o $45^{\circ}$ do país (de um total de 5570 municípios) (Instituto Brasileiro de Geografia e Estatística [IBGE], 2017). Nota-se, assim, que Londrina ocupa uma posição de destaque quanto à sua população e produção econômica e abarca, para fazer frente ao elevado volume de 
demandas administrativas, um expressivo número de processos na esfera pública. Nesse sentido, o projeto conduzido pelo NIGEP se reveste de importância e oferece oportunidade de os conhecimentos acadêmicos transpassarem os limites da universidade em prol do desenvolvimento social.

O subprojeto dedicado à SMOP almejou, principalmente, a padronização e otimização dos fluxos dos processos associados à secretaria, que dizem respeito às obras públicas empreendidas pela PML e às comerciais e residenciais de pessoas físicas e jurídicas. O NIGEP realizou os trabalhos por setores da SMOP, considerando aqueles que delimitavam atividades de natureza semelhante. Assim, após avaliar a estrutura da SMOP, observou-se que se encontrava dividida em diretorias: de Edificações Públicas; Serviços Urbanos e Pavimentação; Projetos; Aprovação de Projetos; Loteamentos e Gestão Administrativa. Pelo estado avançado dos trabalhos, a análise de processos aqui descrita refere-se à Diretoria de Loteamentos (DL). Trata-se do setor da PML responsável por processos de avaliação dos loteamentos propostos no município e, portanto, atua intermediando relevantes impactos ambientais, sociais e econômicos na região. No entanto, a DL encontrava dificuldades para atender suas funções, tornando pouco dinâmico o contexto de negócio para loteadores e PML.

A seguir são expostos conceitos e ferramentas que concernem à análise e gestão de processos, seguidos pelos procedimentos metodológicos utilizados, resultados e conclusões.

\section{Processos de negócios}

Os processos nas organizações mostram-se um elemento-chave àquelas que desejam se transformar para o sucesso, e, portanto, devem ser objetos de atenção e melhoria (Kilmann, 1995). Eles são definidos pela Association of Business Process Management Professionals (ABPMP, 2013, p. 35) como "uma agregação de atividades e comportamentos executados por humanos ou máquinas para alcançar um ou mais resultados". Assim, os processos entremeiam todas organizações, na medida em que estas se caracterizam por empreender atividades coletivas (Chesterton, 2010).

A adequada identificação de um processo envolve a delimitação dos elementos que podem constituí-lo: eventos, atividades, pontos de decisão, atores, objetos, resultados e clientes (Dumas et al., 2013). Os eventos consistem em ações que não possuem duração (imediatas), o que os diferenciam das ocorrências assumidas como atividades. Os pontos de decisão são momentos em que uma escolha deve ser empreendida, a qual afetará o fluxo do processo. Este abarca, ainda, atores (exercem alguma ação, podendo ser pessoas, organizações e softwares), 
objetos (materiais e imateriais), resultados e clientes (consomem os resultados, que são positivos quando agregam valor aos atores envolvidos e negativos, quando não o fazem) (Dumas et al., 2013). O campo de estudo que articula tais elementos em pesquisas e na prática é denominado Gestão de Processos de Negócio, ou Business Processes Management (BPM), (Ongena \& Ravesteyn, 2020), o qual tem recebido atenção de uma diversidade de públicos além do acadêmico desde os anos de 1990 (Barbu et al., 2020; Brocke \& Rosemann, 2015; Pereira \& Freitas, 2019). Ele pode ser definido como "um sistema integrado para gerir o desempenho do negócio pelo controle de seus processos de ponta a ponta" (Hammer, 2015, pp. 4-5, tradução nossa). Na esfera pública, a adoção do BPM em organizações brasileiras tem sido crescente nos últimos anos (Calazans et al., 2016).

Em síntese, o BPM envolve a administração de eventos, atividades, pontos de decisão, atores, clientes, objetos e resultados de maneira a alcançar melhorias nos processos. O sentido que tais melhorias assumem são quatro (Dumas et al., 2013): tempo, custo, qualidade e flexibilidade. Ademais, o BPM encerra diversas fases, que o fazem dinâmico e requerem esforços contínuos para a manutenção dos processos organizacionais. Tais fases compreendem o planejamento, análise, desenho, implementação, monitoramento e controle e refinamento (ABPMP, 2013).

\section{Mineração de processos}

A mineração de processos (MP) trata de uma metodologia cujo objetivo é extrair informações por meio dos registros das atividades, ou log de eventos, realizados pela organização ( Aalst, 2011), visando à detecção de erros, inconsistências ou pontos de melhoria (Reyes et al., 2019). Ela “fornece uma coleção genérica de técnicas para transformar dados de eventos em informações valiosas, ideias de aprimoramento, previsões e recomendações" ( Aalst, 2018, p. 105, tradução nossa). A MP abarca três perspectivas sobre as quais se embasam a mineração, que correspondem à do processo, no qual o foco é o seu ordenamento; à organizacional, em que os papéis e as relações daqueles que realizam as atividades são destacados; e à perspectiva centrada nos casos (um item processado), em que indicadores a ele associados e/ou sua posição no fluxo são elementos de interesse (Dongen et al., 2005).

O interesse na MP está aumentando, o que pode ser observado na elevada disponibilidade de ferramentas comerciais como Disco (Fluxicon), Celonis Process Mining (Celonis), Process-Gold Enterprise Platform (ProcessGold), ARIS PPM (Software AG), QPR ProcessAnalyzer (QPR), SNP Business Process Analysis (SNP AG), minit (Gradient ECM), 
Melan, R. L., Silva, H. F., Amâncio-Vieira, S. F., \& Baccarin, E. (2020, jul./dez.). Mineração de processos em um órgão público: estudo da diretoria de loteamentos da Prefeitura Municipal de Londrina (PR)

myInvenio (tecnologia cognitiva), Mineração de Processamento Perceptivo (Lexmark), entre outras (Aalst, 2018). Complementar ao BPM, a MP pode exercer diversos papéis relevantes em seu ciclo de vida, como design do processo, seu monitoramento e, se necessário, ajuste; e diagnóstico e análise de requisições face a novas situações que emergiram. Portanto, a MP torna-se uma ferramenta de elevada importância, atuando na descoberta dos processos, na análise de conformidade (comparando os dados provenientes do log de eventos com os modelos especificados) e em sua melhoria (Aalst, 2011). O log de eventos, para realização da MP, requer os seguintes atributos (Greyling \& Jooste, 2017): identificação do evento, ou seja, das atividades; registro de tempo; atividade, que é a caracterização do evento; recurso (responsável pela ocorrência do evento); e identificação do caso (atribuição de valor aos casos que permitam sua identificação).

\section{Metodologia}

O trabalho se caracteriza como estudo de caso misto (quantitativo e qualitativo), descritivo e exploratório, com recorte longitudinal e baseado em dados primários e secundários, cujo problema endereçado foi a descoberta e melhoria de processos da Diretoria de Loteamentos da PML. A abordagem quantitativa se perfaz na aproximação da realidade a ser estudada, nos métodos de coleta e análise dos dados (Creswell, 2010), os quais aqui se referem, nesta ordem, a indicadores objetivos provenientes de dados processuais da citada diretoria, ao levantamento destes por sistemas dedicados à gestão de protocolos e à sua análise a partir de ferramentas quantitativas. Tais indicadores foram censitários (todos processos), bem como aqueles provenientes da MP (prazos médios, frequência de eventos por setor entre outros).

Já a classificação qualitativa decorre de avaliação caso a caso de processos da diretoria selecionados, visando à sua compreensão em profundidade, e à elaboração de fluxograma baseado nas normas que direcionam as atividades da diretoria.

Por retratar algumas medidas-resumo dos processos da Diretoria de Loteamentos (indicadores censitários e da MP), a categoria que abarca as principais causas dos problemas associados aos processos (avaliação caso a caso) e seus modelos especificados por normas (fluxograma legal), a pesquisa é descritiva. Elaborou-se o fluxograma por meio do software Bizagi ${ }^{\circledR}$. A MP almejou, além dos indicadores referidos, a descoberta dos processos, ou seja, a sua observação tal como foram realizados, o que fornece o caráter exploratório do estudo. Para tanto valeu-se do software Disco®. A utilização deste se tornou possível após a equipe do NIGEP formar parceria com a empresa holandesa Fluxicon, detentora do software e sua 
representante no Brasil, Strongit. A descoberta dos processos da DL envolveu a observação dos fluxos entre setores, a integração entre eles e sua variabilidade.

Os dados fornecidos pela PML à análise quantitativa foram do tipo secundário, considerando a sua obtenção pelo Sistema Integrado de Processos (SIP) e disponibilizados em planilha eletrônica. Eles corresponderam a uma população de 544 casos no período de 2007 a 2019 (parcial). Já aqueles utilizados na avaliação caso a caso, caracterizaram-se como primários, pois foram coletados do Sistema Eletrônico de Informações (SEI). O SEI registra as movimentações dos processos da PML, incluídos, portanto, os da Diretoria de Loteamentos, e contém dados diversos como e-mails, contratos, comunicações internas, entre outros. A amostragem para análise caso a caso resultou em 116 processos, com grau de confiança de 90\% e margem de erro de, aproximadamente, $7 \%$.

Em síntese, as análises se iniciaram pela etapa quantitativa, calculando-se os indicadores censitários e dispondo-os em gráfico por meio de planilhas eletrônicas. Nesta etapa procedeuse, ainda, à MP, sendo que os indicadores e os fluxos processuais foram obtidos pelo Disco®, após a entrada dos dados. Verificaram-se, no próprio software, setores mais sensíveis (prazos e quantidade de eventos elevados), a integração entre setores, o número destes, entre outros elementos. Em seguida, a análise caso a caso baseou-se na leitura dos processos e identificação de motivos recorrentes para as dificuldades identificadas na etapa anterior. Por fim, após elaboração do fluxograma legal, forneceu-o, junto dos resultados obtidos e sugestões de melhoria, à DL, caracterizando, por fim, o estudo como prescritivo.

\section{Resultados obtidos e análise}

A seguir, são descritos e discutidos os dados referentes à abordagem quantitativa e, posteriormente, à qualitativa. A primeira trata dos indicadores censitários e da mineração, sendo expostos os gráficos que resultaram do Disco®. Na segunda, os resultados e discussões das análises qualitativas são apresentados e servem para se aprofundar nas origens de problemas identificados na etapa quantitativa como a alta variabilidade e tempo dos processos.

\subsection{Etapa quantitativa}

Conforme a Figura 1, entre 2007 e 2019, os casos apresentaram alta oscilação de frequência (total de processos), acompanhada pelos casos que se arquivaram. Houve baixa relação entre os processos deferidos e aqueles protocolados, o que sugere problemas em seu tratamento (interna e/ou externamente). Aumentaram-se os casos pendentes em 2018 (maior 
quantidade em todo o período), mesmo que o total de processos não possua o mais alto número nesse ano. Isso indica potenciais dificuldades internas para lidar com eles.

Figura 1 - Casos processos na diretoria de loteamentos

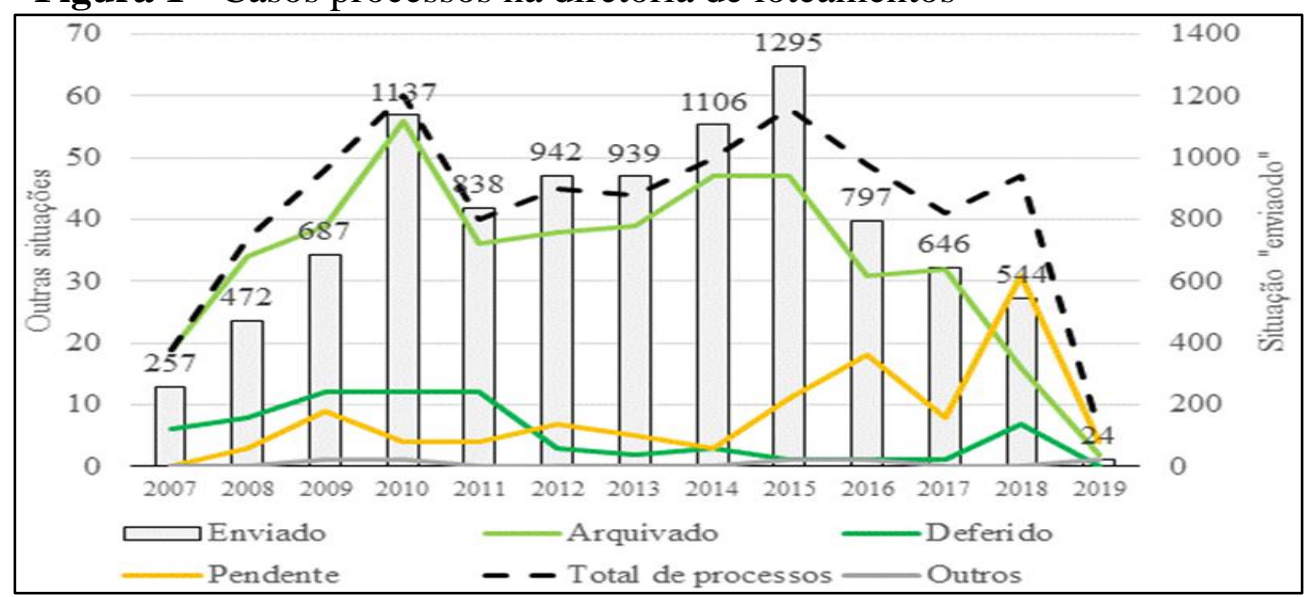

Fonte: Elaborado pelos autores (2020).

O tempo médio dos casos deferidos e arquivados, ou seja, daqueles que incorreram em um ciclo "completo" na Diretoria de Loteamentos e suas divisões associadas também foram analisados. O período elevado de processamento, de 984 dias, expressa sua baixa dinâmica, com potenciais dificuldades aos loteadores em fazerem jus a resultados projetados e à PML, devido a perdas de oportunidade econômica. Um caso avaliado pela diretoria pode levar vários anos até sua aprovação, considerando que os deferidos assumem tipos distintos de processos até alcançarem essa condição.

Já o percentual dos casos movimentados por setores indica que a maior parte das movimentações ocorrem na própria Diretoria de Loteamentos, seguida pela Gerência de Planejamento Físico Territorial - IPPUL. Observou-se a natureza diversa dos setores envolvidos como o Instituto de Pesquisa e Planejamento Urbano de Londrina (IPPUL), a Secretaria Municipal de Ambiente (SEMA) e a Procuradoria Geral do Município.

Para a mineração de processos, realizaram-se algumas modificações no log de eventos recebido (planilha com os casos). Este requereu a definição da data inicial dos eventos (a partir do protocolo e movimentação do processo); o filtro de casos arquivados e a abreviação da descrição do setor. Do filtro para retenção dos casos arquivados, ele se mostrou necessário na medida em que se almejou avaliar apenas aqueles que representaram conjuntos completos de eventos. A abreviação da descrição do setor visou o melhor encaixe visual dos mapas gerados na MP.

Os atributos do log de eventos (Greyling \& Jooste, 2017) são descritos no Quadro 1. Nota-se sobreposição entre dois deles: a identificação do evento e o recurso. Em vez de o 
primeiro abarcar a atividade realizada, contém o setor que a desenvolveu. Apesar dessa aproximação representar limitações ao estudo dos processos da DL, impossibilitando visualizar, em detalhes, a quantidade e o tempo médio de atividades desenvolvidas em seus setores, oferece dados relevantes à melhoria dos processos. Portanto, a MP embasou-se nas perspectivas organizacionais e centradas nos casos (Dongen et al., 2005), ou seja, o foco de análise recaiu, respectivamente, nos fluxos entre setores e em indicadores associados aos casos. Adicionalmente, atribuiu-se o tipo de processo ao campo "Other" do software Disco ${ }$, o que possibilitou visualizar a quantidade de tipos processuais desempenhados.

Quadro 1 - Atributos do log de eventos utilizado na MP

\begin{tabular}{|c|c|}
\hline Atributo & Descrição \\
\hline $\begin{array}{l}\text { Identificação } \\
\text { do evento }\end{array}$ & $\begin{array}{l}\text { O campo "DESC SETOR" na planilha disponibilizada, posteriormente abreviado, o qual } \\
\text { contém o setor responsável pelo evento. Ele foi atribuído à variável “Activity" no Disco® }\end{array}$ \\
\hline $\begin{array}{l}\text { Registro de } \\
\text { tempo }\end{array}$ & $\begin{array}{l}\text { Os campos "DTA_PROTOCOLO" e "DTA_MOVIMENTO, os quais contêm a data de } \\
\text { encaminhamento do processo para realização do próximo evento, atribuído ao } \\
\text { "Timestamp" no Disco } \AA\end{array}$ \\
\hline Atividade & $\begin{array}{l}\text { Por meio da identificação textual do evento (abreviatura), conforme indicado acima, já se } \\
\text { tornou possível sua caracterização. }\end{array}$ \\
\hline Recurso & Trata-se do setor responsável pela atividade, que já fora utilizado para identificar o evento \\
\hline $\begin{array}{l}\text { Identificação } \\
\text { do caso }\end{array}$ & $\begin{array}{l}\text { O campo "NRO_PROCESSO", o qual contém o número (único) do processo (caso), } \\
\text { atribuído ao "ID Case" no Disco® }\end{array}$ \\
\hline
\end{tabular}

Fonte: Elaborado pelos autores (2020).

Os maiores fluxos de eventos por setor podem ser observados na Figura 6, onde os retângulos de cores mais acentuadas e as setas mais espessas representam quantidades mais elevadas. Os círculos em destaque, de números 1 e 2, são, nesta ordem, a Diretoria de Loteamentos (1313 eventos) e a Gerência de Planejamento Físico Territorial - IPPUL (1240 eventos), setores associados a atividades de gestão. Esta característica sugere que muitos eventos consistem em simples encaminhar de casos, ou seja, com potencial de serem enviados ao destino fim de maneira direta a partir de regras/diretrizes estabelecidas.

$\mathrm{Na}$ Figura 2 é visualizado um grande fluxo de processos entre a Diretoria de Loteamentos e a Praça de Atendimento - Obras (círculo em destaque com número 3). Este setor interage diretamente com os loteadores, por exemplo, recepcionando documentos e encaminhando demandas que resultaram de análises da SMOP. Em ambas as direções do fluxo, da Praça para Diretoria e desta à Praça, existem mais movimentações do que casos transitados, o que indica potenciais inadequações daquilo que fora disponibilizado pelos loteadores e/ou 
ausência de documentos requeridos. Para os processos e casos entre a Diretoria de Planejamento Urbano - IPPUL (círculo em destaque com número 4) e a Gerência de Planejamento Físico Territorial - IPPUL, tal situação também é vislumbrada.

O tempo médio dos eventos movimentados por setor são indicados na Figura 2, com os retângulos de cores mais acentuadas e setas mais espessas indicando maiores valores. A Gerência de Cadastro - SMOP, destacada pelo círculo vermelho com número 1, possui o maior tempo médio, qual seja cerca de 17 meses, seguida pela Praça de Atendimento - Obras, representada pelo círculo de número 2, com aproximadamente 4 meses. Existe(m) evento(s) com elevado tempo de processo, considerando que a mediana dos valores é bastante diferente: de forma respectiva, 4 e 22 dias.

Figura 2 - Frequência absoluta de eventos para todos os tipos de processos

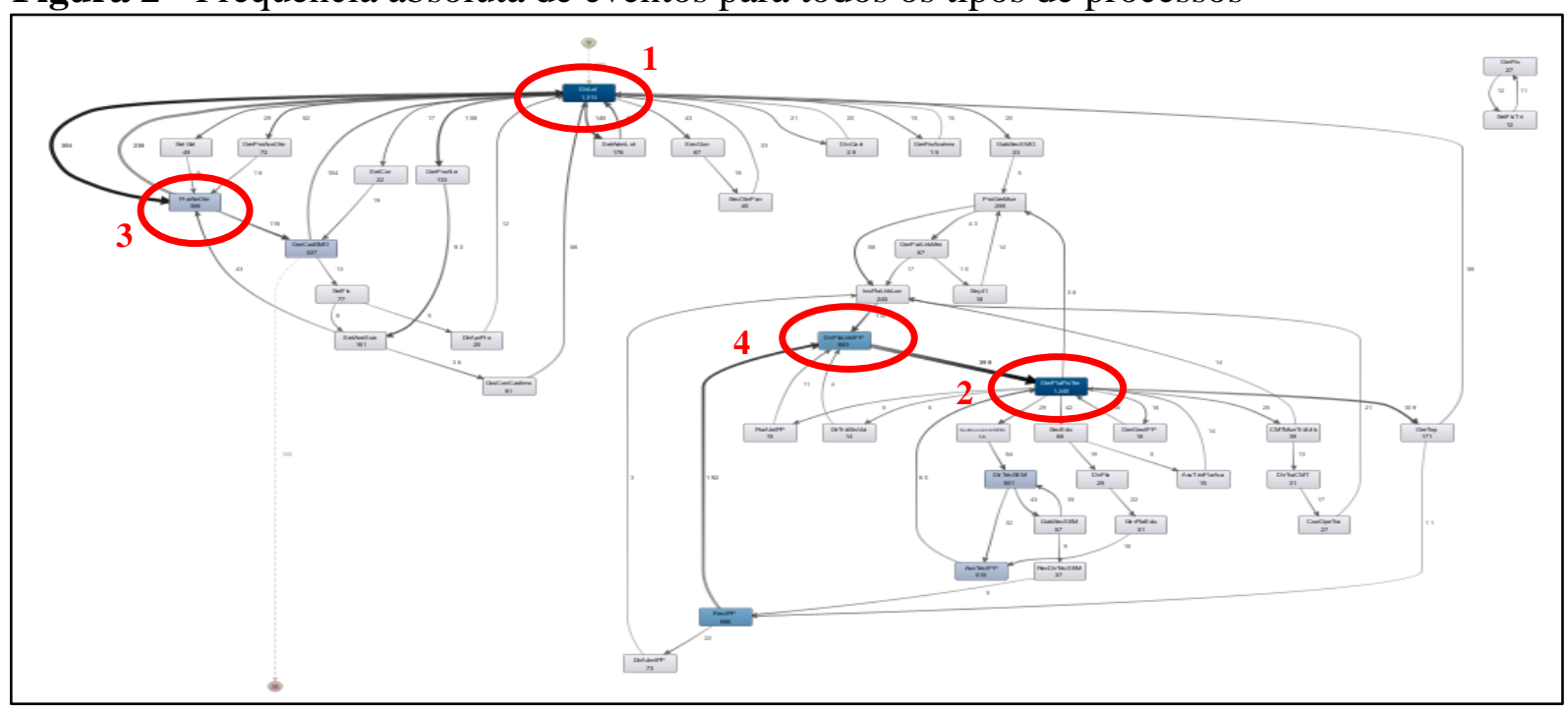

Fonte: Elaborado pelos autores por meio do software Disco® (2020).

A seta mais espessa na Figura 3, dos fluxos entre a Diretoria de Loteamentos (círculo vermelho 3) e a Praça de Atendimento - Obras, representa o tempo médio de cerca de uma hora e perfaz o maior valor entre os fluxos. Assim, os processos cuja origem é aquele setor e o destino são especialmente morosos, dada esta combinação: Praça de Atendimento - Obras e fluxo entre ela e a Diretoria de Loteamentos com tempos médios elevados. Ressalta-se que os dados fornecidos impossibilitaram observar a duração dos encaminhamentos diretos entre dois setores. No entanto, devido às Figuras 2 e 3 conterem 36,4\% das atividades, ou seja, existirem setores intermediários, visualizou-se o tempo médio entre setores.

As análises dos mapas de processos representados pelas Figuras 2 e 3, em conjunto, permitiram observar a Praça de Atendimento - Obras, enquanto um setor de particular interesse à melhoria dos processos de loteamentos. Além de apresentar intensa carga de atividades, 
possui tempo médio de trabalho elevado, o que caracteriza um potencial gargalo. Essa conjectura também é válida para o fluxo de processos entre o setor e a Diretoria de Loteamentos. Os mapas sugerem, ainda, possibilidade de maior integração entre fluxos processuais, pois notase a formação de dois blocos de setores distintos (linhas pontilhadas na Figura 3).

Figura 3 - Tempo médio dos eventos para todos os tipos de processos

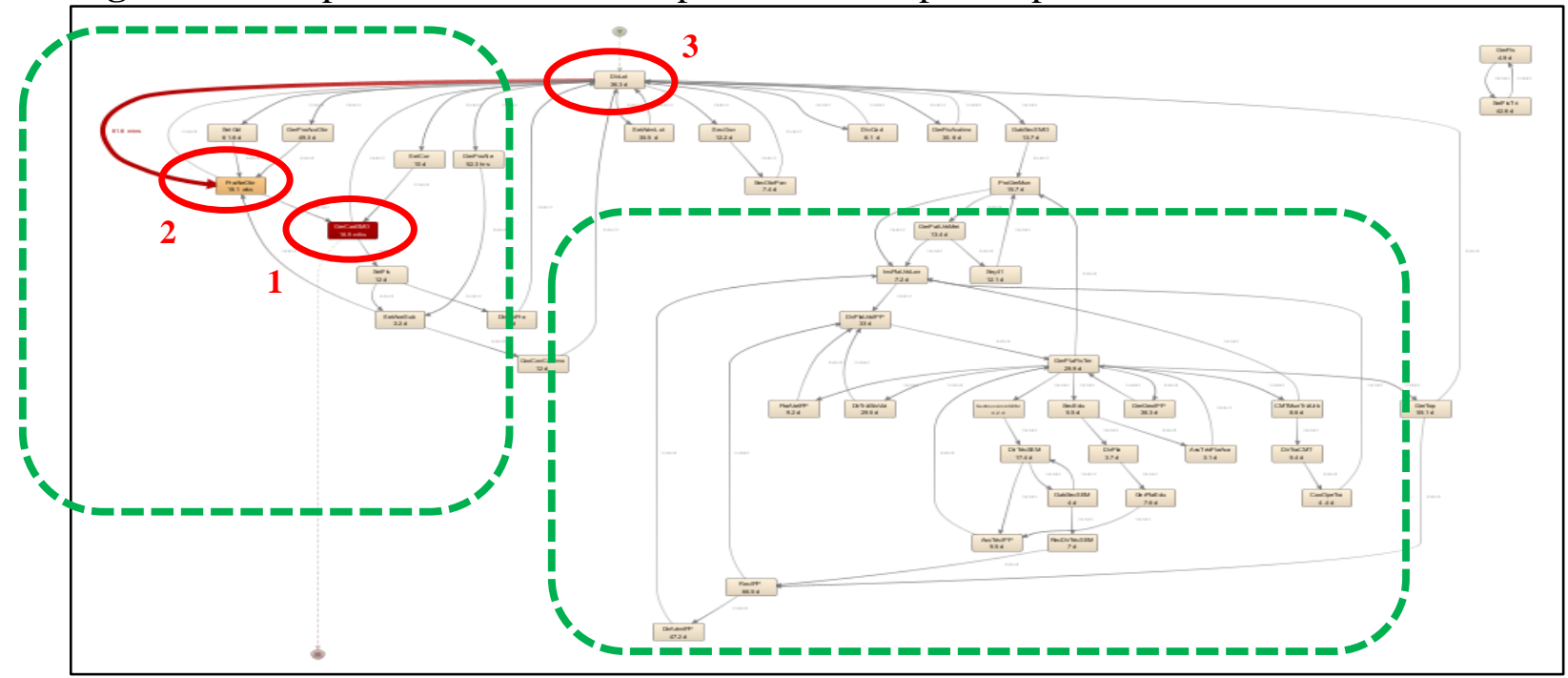

Fonte: Elaborado pelos autores por meio do software Disco (2020).

Os indicadores mostrados no Quadro 2 complementam as análises acima. É notória a elevada quantidade de eventos frente a de casos, o que sugere processos complexos para a aprovação de loteamentos na PML. Tal complexidade é reiterada no número de setores envolvidos nesses processos, qual seja de 110. Ademais, os casos, em média e pela mediana, estão sujeitos a grandes intervalos de tempo para sua resolução.

Quadro 2 - Indicadores obtidos dos processos da diretoria de loteamentos

\begin{tabular}{|c|c|c|c|c|} 
Eventos & Casos & Setores & $\begin{array}{c}\text { Duração média dos } \\
\text { casos }\end{array}$ & $\begin{array}{c}\text { Duração mediana dos } \\
\text { casos }\end{array}$ \\
\hline 8166 & 436 & 110 & 32,4 meses & 21 meses \\
\hline
\end{tabular}

Fonte: Elaborado pelos autores por meio do software Disco $®$ (2020).

Por fim, observou-se, por meio do Disco®, que a maior parte dos casos não apresentavam padrões de fluxo iguais, ou seja, encaminhamentos pelos mesmos setores na mesma ordem. Os 436 casos foram agrupados em 370 tipos de fluxos, expressando a alta variabilidade destes. Destaca-se, também, que a maioria dos casos descreveu caminhos únicos pelos setores, o que indica a grande flexibilidade processual e, dessa maneira, tempos e custos de execução expressivos. 


\subsection{Etapa qualitativa}

Identificaram-se alguns pontos de atenção recorrentes na análise qualitativa, sendo o mais frequente a ausência de documentos e/ou informação que deveriam ser disponibilizados pelo loteador. Além disso, o longo período sem movimentação dos casos também constitui um problema potencial, com o tempo parado chegando a mais de um ano. Outros pontos estão associados à morosidade para avaliação dos casos ou para se obter informação interna, duplicidade de processo, inconsistência de parecer técnico (pontos de discordância entre diferentes setores ou parecer ambíguo) e ausência de descrição de atividade.

A elaboração do fluxograma com embasamento nas normas que direcionam os trabalhos da Diretoria de Loteamentos caracterizou a última etapa da forma qualitativa dos esforços aqui descritos. Observou-se que as atividades atualmente desempenhadas na apreciação dos loteamentos do município não encontram, de forma geral, óbices à sua melhoria nas diretrizes que as determinam. Elas se constituem amplas e fornecem, portanto, certa discricionariedade à Diretoria de Loteamentos para especificá-las.

Em posse dos resultados dos indicadores censitários, MP, avaliação caso a caso e fluxograma, ao NIGEP foi permitido tecer recomendações para melhorias dos processos. Estas assumiram três sentidos, de tempo, custo e qualidade (Dumas et al., 2013) e, portanto, representaram relevantes potenciais de ganhos nos serviços internos e externos prestados pela SMOP em particular e pela PML em geral. Assim, o tempo, a elaboração de listas de documentos a serem disponibilizados pelos requerentes e a verificação prévia de características elementares dos projetos poderiam implicar menos movimentações dos casos e períodos menores de análise. Sugere-se, ainda, maior integração entre os diferentes setores relacionados aos processos, eliminando simples encaminhamentos da Diretoria, bem como o estabelecimento de prazos para os loteadores movimentá-los antes do arquivamento. Por fim, a elaboração de manual de procedimentos interno e externo para fazer frente à complexidade dos processos e a tramitação paralela dos casos têm potencial de mitigar o tempo de análise dos loteamentos. Em se tratando do custo, os processos vinculados à Diretoria possuem a maior parte dele representada pelo trabalho humano, na figura de servidores com salários mensais fixos. Portanto, a diminuição dos tempos de processo será acompanhada por queda no custo por caso.

Os loteamentos abarcaram elevada flexibilidade, a qual se mostrou prejudicial à eficiência e eficácia dos trabalhos da Diretoria de Loteamentos ou sob sua responsabilidade. Em reuniões com a servidores da SMOP, evidenciou-se o alto nível de insatisfação com o parco 
controle dos processos, expresso, por exemplo, em dúvidas sobre quais procedimentos adotar para endereçá-los. Portanto, a elaboração de manual de procedimentos vem superar esse obstáculo, imbuindo os trabalhos com maior qualidade.

\section{Considerações finais}

O projeto de melhoria dos processos vinculados à SMOP se mostrou de elevado potencial a uma de suas principais instâncias, a Diretoria de Loteamentos. Ela localiza-se no centro de preocupações no planejar urbano do município, considerando os impactos ambientais, sociais e econômicos dos loteamentos. Por meio de método misto de análise de dados, observou-se que os processos são bastante complexos, abarcam tempos longos de avaliação e carecem de padronização de seus fluxos. Assim, a equipe do NIGEP realizou sugestões com potencial de sanar ou mitigar esses problemas.

Apesar dos dados com que o NIGEP trabalhou não terem possibilitado aplicação mais ampla da metodologia de mineração de processos, ela se mostrou bastante útil às análises empreendidas. Além de ocasionar elevada eficiência no tratamento dos dados, permitiu visualizar fluxos processuais e indicadores atrelados a estes, aos casos e aos setores da Diretoria de Loteamentos, fundamentando as sugestões de melhoria e complementando/reiterando os resultados das outras formas de análise. Portanto, este trabalho representa importante contribuição a tal metodologia, na medida em que desvela potencialidades de ganhos analíticos mesmo em face de dados parcos. As atividades do NIGEP continuam na Diretoria de Loteamentos, sendo que se disponibilizou a ela as sugestões de melhoria elencadas e o fluxograma legal que servirão para discussão da operacionalidade das sugestões e sua especificação, bem como de substrato a novas propostas sugeridas pelos servidores da SMOP.

\section{Referências}

Aalst, W. van der. (2018). Spreadsheets for business process management: using process mining to deal with "events" rather than "numbers"? Business Process Management Journal, 24(1), 105-127. https://doi.org/10.1108/BPMJ-10-2016-0190

Aalst, W. M. P. van der. (2011). Process mining: discovery, conformance and enhancement of business processes (1st ed.). Springer.

Association of Business Process Management Professionals. (2013). BPM CBOCK: guia para o gerenciamento de processos de negócio: corpo comum de conhecimento: ABPMP BPM CBOK V3.0 (1st ed.). ABPMP Brasil. 
Melan, R. L., Silva, H. F., Amâncio-Vieira, S. F., \& Baccarin, E. (2020, jul./dez.). Mineração de processos em um órgão público: estudo da diretoria de loteamentos da Prefeitura Municipal de Londrina (PR)

Barbu, A., Simion, P. C., Popescu, M. A. M., Marcu, I. C. C., \& Popescu, M. V. (2020). Exploratory study of the BPM tools used by romanian industrial service companies to increase business performance. TEM Journal, 9(2), 546-551. https://doi.org/10.18421/TEM92-16

Brocke, J. vom, \& Rosemann, M. (2015). Introduction. In J. vom Brocke \& M. Rosemann (Eds.), Handbook on Business Process Management 1: introduction, methods, and information systems (2nd ed., pp. 1-2). Springer.

Calazans, A. T. S., Kosloski, R. A. D., \& Guimarães, F. de A. (2016). Proposta de modelo de medições para contratação do gerenciamento de processo de negócio (business process management - BPM). Journal of Information Systems and Technology Management, 13(2), 275-300. https://doi.org/10.4301/S1807-17752016000200007

Cantarino, N., \& Müller, V. (2020). Como evitar o risco de uma política de bem-estar anacrônica. Nexo. https://www.nexojornal.com.br/ensaio/debate/2020/Como-evitar-o-riscode-uma-política-de-bem-estar-anacrônica

Chesterton, G. K. (2010). Introdução: a importância dos estudos organizacionais. In C. Grey (Ed.), Um livro bom, pequeno e acessivel sobre estudos organizacionais (2nd ed., pp. 2751). Bookman.

Creswell, J. W. (2010). Projeto de pesquisa: métodos qualitativo, quantitativo e misto (3rd ed.). Artmed.

Dongen, B. F. van, Medeiros, A. K. A. de, Verbeek, H. M. W., Weijters, A. J. M. M., \& Aalst, W. M. P. van der. (2005). The ProM framework: a new era in process mining tool support. In G. Ciardo \& P. Darondeau (Eds.), Lecture Notes in Computer Science (pp. 444454). Springer.

Dumas, M., Rosa, M. L., Mendling, J., \& Reijers, H. A. (2013). Fundamentals of Business Process Management (1st ed.). Springer.

Ferrer, F. (2018). Gestão pública eficiente: colocando o cidadão no centro das atenções (1st ed.). Alta Books.

Greyling, B. T., \& Jooste, W. (2017). The application of business process mining to improving a physical asset management process: a case study. South African Journal of Industrial Engineering, 28(2), 120-132. https://doi.org/10.7166/28-2-1691

Hammer, M. (2015). What is business process management? In J. vom Brocke \& M. Rosemann (Eds.), Handbook on Business Process Management 1: introduction, methods, and information systems2 (2nd ed., pp. 3-16). Springer.

Instituto Brasileiro de Geografia e Estatística. (2017). Produto interno bruto dos municípios. https://cidades.ibge.gov.br/brasil/pr/londrina/pesquisa/38/47001?tipo=ranking

Kilmann, R. (1995). A holistic program and critical success factors of corporate transformation. European Management Journal, 13(2), 175-186. https://doi.org/10.1016/0263-2373(95)00005-6 
Universidade Estadual de Londrina. (2020). Núcleo Interdisciplinar de Gestão Pública. http://www.uel.br/projetos/nigep/

Ongena, G., \& Ravesteyn, P. (2020). Business process management maturity and performance: a multi group analysis of sectors and organization sizes. Business Process Management Journal, 26(1), 132-149. https://doi.org/10.1108/BPMJ-08-2018-0224

Pereira, J., \& Freitas, A. P. (2019). Towards a characterization of BPM tools' simulation support: the case of BPMN process models. International Journal for Quality Research, 13(4), 783-796. https://doi.org/10.24874/IJQR13.04-02

Prefeitura de Londrina. (2020). Londrina em dados 2019 (ano base 2018). https://www.londrina.pr.gov.br/londrina-em-dados-2018-ano-base-2017

Reyes, S. C. F., Castro, A. D., Pérez, W. G., Lazcano, P. R., \& Pérez, L. L. (2019). Caracterización de la producción científica en el área disciplinar de la minería de proceso. Investigación Bliblioteconológica, 33(78), 193-216. https://doi.org/10.22201/iibi.24488321xe.2019.78.57925 